\title{
Volatility Asset Pricing Model as an Alternative Approach? ${ }^{\#}$
}

Robert G. KUKLIK* - Vladislav VACEK ${ }^{* *}$

\section{Introduction}

The worldwide market collapse of the autumn 2008 as the sharp prices fall had many causes: apart from the effects of several long-time underlying general fundamentals, e.g. the political decisions built into the populist community housing law US during the president Clinton's era, the tax cuts in 2000 and 2005 deployed by the George W. Bush's Administration and last but not least a political pressure on the Federal Reserve's Alan Greenspan to keep the key interest rates low and the interest rates cut in June 2003 by the ECB to their historical minimum. All that opened the gates to rapacity of the banks, false serenity feeling of the regulators enhanced by the oblique, cross-interested approach of the rating agencies. The 7\% point plunge of DJ Industrial Average meant that in just a few hours more than $\$ 1.6$ trillion was sliced off the value of American industry's capitalization and $\$ 5$ trillion worldwide. However, there still can be posed a question as to what was the real framework of this financial disaster - a purely human, unsupported optimism. The so called subprime mortgages that undermined the bank's portfolios were written on the false assumptions that what had been seen before would more or less persist into the future, in other words the housing prices would keep rising defaults rates would stay within a forecast range and the sophisticated strategies so far seemingly working would keep doing so. Unfortunately, it is well known that this kind of paradigm has always led to every financial "bubble" in the history - as from the Dutch tulips in the $17^{\text {th }}$ century to the so called dot-coms at the break of the last decade in America.

\# This paper is result of research project IGA F1/6/2013 financed by Internal Grant Agency of University of Economics in Prague.

* Robert G. Kuklik, MBA - Ph.D. student; Department of Banking and Insurance, Faculty of Finance and Accounting, University of Economics, Prague, W. Churchill Sq. 4, 13067 Prague 3, Czech Republic; <elf.rob@centrum.cz>.

** Ing. Vladislav Vacek - Ph.D. student; Department of Banking and Insurance, Faculty of Finance and Accounting, University of Economics, Prague, W. Churchill Sq. 4, 13067 Prague 3, Czech Republic; <xvacv15@vse.cz>. 
But this latter crisis was magnified by a new phenomenon of the contemporary era: overconfidence in our understanding of the markets functioning based on the increasingly sophisticated investment strategies involving esoteric products and supported by accordingly complicated models. From all this it appears that for example the general validity of Efficient Market Hypothesis (EMH), embodied for example in the Capital Asset Pricing Model, Single Index Model, Black \& Scholes Model for pricing options, etc., has been for a while in doubt due to various reasons, e.g. that in the efficiency equilibrium with all investment horizons being identical, the market performance would have to come to a halt. This concept assumes that ultimately markets reflect all known information and follow the so called "random walk" process, with a view that security returns are normally distributed without an incidence of any significant price "explosions" and their corresponding subsequent "implosions". But evidence suggests that extreme outliers in the stock and currency markets with the prices being serially dependent are far more common than the random walk model (RWM) would predict. Various researchers, e.g. LeRoy (1973), Lucas (1978) and others argue that this model and the EMH are not always two enmeshed processes but going hand in hand only in hypothetically a riskless market environment.

The RWM and EMH are two different concepts. The latter is an inverse function of the information entropy of the market system based on its volatility, as well the serial dependence of the prices. In other words on the volume of information absorption affecting the prices' risk profile, assuming away a certain level of the market's information asymmetry, whereas the random walk process insists on the normal, in time repetitive distribution of returns.

The notion that "in an efficient capital market there will be likely relationships between risk and return" (Sharpe, 1991, pp.142) in a strict view according to the Markowitz's mean-variance maxim have become generally doubtful. Further, the role of the phenomenon of information asymmetry, together with different patterns of investors' behaviour is indisputable. "Effective functioning of the capital markets is conditioned upon the activities of fully informed participants. This is not the case of not regulated market" (Musílek, 2002, p.107). Therefore, the "rational" investors cannot in fact rely on a rather comforting message conveyed by the EMH that all you need to do to obtain an "expected" return is to take the appropriate level of commensurate risk. 
Such a rule can perhaps apply as a matter of temporary exception to some groups of investors in certain large, fluid, developed and dynamic markets. The flow of time of the market seems to be rather like a continuum of serial dependencies of security returns besprinkled with the volatility "bubbles" and "troughs", with the pockets of "efficient" investment behaviour of different size, popping from time to time up and down.

Of course, at the first view the picture appears to be rather disorderly without any pattern which obviously due to a diversity of influencing factors cannot be considered as a really homogeneous entity. Extremities of the price volatility swings are however an integral part of the market performance and not just aberrations that can be simply ignored. Therefore, under these circumstances it is possible to postulate that such a structure can be broken into small parts, fractals, each a small-scale representation of the whole even though in too seemingly featuring chaos. Important here are not the overall market value changes translated to an individual return by for example the historically determined coefficient $\beta$, but the future expectations of the market volatility and a degree of possible influence of the past prices' performance on a particular security return. In this context for example any consideration of distinction in categories such as a doubtful "risk free" rate, the "risk premium" and the "unsystematic" risk/return becomes rather irrelevant.

\section{Asset Pricing Models examples the CAPM, SIM, and MIM}

The standard form of the general equilibrium relationship for assets return (implying the cost of capital) was developed independently in the 60s' by Sharpe, Lintner and Mossin and based on the early ideas of Bachelier, stating that normally distributed price changes are statistically independent, to follow the random walk pattern and therefore unpredictable. However, it also says that their fluctuations can be described by the law of chance thus making the investment risk measurable and therefore manageable. The central idea of the Capital Assets Pricing Model $(C A P M)$ is the Fama's well known Efficient Market Hypothesis arguing that in an ideal, efficient market, all relevant information is already absorbed into a security price today. In other words, the yesterday's price change does not influence the today's, tomorrow's, etc. performance, so each price change is independent from the last and the market does not possess any "memory". Obviously, from the point of view of the real world such assumptions are rather unrealistic. 
Various past research e.g. Dodd (1980), Lo and MacKinlay (1988), etc. has indicated that the price changes are not always serially independent of each other thus expressing doubts whether their dispersion fits under all occasions the normal distribution. The extreme price swings are within the norm in the financial markets where it is also certainly difficult to assume that one and the same distribution can describe all and every type of financial asset. Naturally, commodities for example do not vary in the same way as equities or fixed interest securities and the concept of "riskless" return is nowadays also if nothing but doubtful. On top of that it is necessary to critically view various more or less unrealistic assumptions concerning the CAPM construction. Also, although the random walk process of serially independent returns is assumed, the coefficient $\beta$ is typically estimated with the aid of various statistical methods using historical market data. The past is therefore assumed to be a good proxy for the present and may be for the future as well. Consequently, considering all such inconsistencies, it is possible to say that the classical CAPM in its historical form, i.e. for a security $j$, expressed as a well known relationship:

$$
\hat{R}_{j}=R_{i}+\beta_{j} \cdot\left(R_{m}-R_{i}\right)
$$

nowadays appears to be a rather artificial construction.

For example Roll (1977) stated that tests performed with any portfolio other than the "true market portfolio" are not tests of the CAPM but they are simply tests whether the portfolio selected as a proxy for the market is "efficient" or not.

Paradoxically, since over an interval of time "efficient" portfolios may even exist, a market proxy can be chosen so that satisfies the implications of the CAPM framework, even though the market portfolio as such is "inefficient". Conversely an "inefficient" portfolio is may be selected as a proxy for the "true" market portfolio and therefore the CAPM rejected, when market itself can be in fact so called "efficient".

A further development in the area of asset pricing models represents the so called Single Index Model, (SIM, the "Market Model"). Casual observation of stock prices reveals that when the market goes up certain number of securities tends to indicate an increase in price, whereas when the market goes down, most securities tend to show a decrease in price. 
This suggests that one reason security returns might be correlated is because of a common response to the market changes, where a useful measure of this correlation might be obtained by relating the return on a stock to the return on the stock market as a whole, represented by the market index. The return on a security $j$ in the period $t$ can be therefore written as also a well known relationship:

$$
\hat{R}_{j t}=\alpha_{j}+\beta_{j} \cdot R_{m t}+\varepsilon_{j t}
$$

In theory, for the case of a completely so called "efficient" market equilibrium absorbing all available information concerning a particular security, the expected value of the return's component $\alpha$ with the random dispersion factor $\varepsilon$, representing the "non-market influences" is zero, hence supposedly performing the "random walk". The key assumption of the SIM is the residual errors $\varepsilon j, \varepsilon i$, for all pairs of securities across their spectrum are serially independent, i.e. $\operatorname{cov}(\varepsilon j i, \varepsilon j t)=0$, and also independent of the market return $R_{m}$. Such assumptions are of course difficult to accept in reality.

On the other hand, for example the Multi-Index Models, (MIM) are an attempt to capture some of the nonmarket influences in the form of a set of economic factors like interest rates or structural groups (industries) that account for common movement in stock prices beyond that accounted for by the market index itself. It is however practically impossible to find a set of variables with covariances that are not market-related. Such models of course whilst allowing analysis of the other than "market factors" influences do in fact conceptually contradict the assumption of the EMH. Nevertheless, the cost of introducing additional indices in the hope of capturing further information is a chance that they are picking up only the "random noise" rather than real influences, notwithstanding a possible multicollinearity problem. The model using the method of multiple linear regression can be generally expressed for a security $j$ 's return in the period $t$ as follows:

$$
\hat{R} j t=a_{j}+b_{j 1} \cdot I_{1 t}+b_{j 2} \cdot I_{2 t}+\ldots+b_{j n} \cdot I_{n t}+\varepsilon_{j t},
$$

where the $I t$ variables represent the added indices, e.g. those concerning particular industry performance, interest rates, P/E, Debt to Equity and Dividend Payout ratios, etc. It can be understandable that the more indices 
added, the more complex things become and the more seemingly accurate the historical correlation matrix is reproduced.

However, there is an evidence, e.g. Cohen \& Pogue (1967), that this type of analytical framework with its further refinements expanded into a generalized Multi Index Model, where the indices are extracted according to their explanatory power from the past data, does not perform as well as the Single Index Model. According to Elton, Gruber (1981), on statistical as well as economic grounds, applying further indices to the SIM led to a decrease in performance since the added variables introduced to the portfolio selection and forecasting process of rather already mentioned random noise than real information. Nevertheless, it is necessary to acknowledge that other influences beyond the efficiency benchmark of the market exist, having a significant and lasting effects on investors' expectations and therefore as such are more or less built into the correlation structure of the security prices.

\section{Volatility Asset Pricing Model (VAPM)}

\subsection{The General framework outline}

The model was developed with the idea that the market price performance discontinuity is a normal, natural phenomenon, reflecting an element of volatile functioning of the capital market, in conjunction with the market price series' concentration, i.e. having small changes in one price caused by small changes in another price "smoothly related" in a sequential continuity.

These factors are the major ingredients in a realistic evaluation of the risk/return relationship concerning the market performance, notwithstanding this process being from time to time complemented by the incidence of volatility clustering in the form of price "bubbles" and their subsequent "bursts".

To put it another way, according to Mandelbrot \& Hudson (2006), the long-term "market memory", in other words the phenomenon of serial price dependence, reflected for example in the Hurst Exponent (the Mandelbrot's "Joseph Effect"), and the parameter a characterizing volatility, expressed as Fractal Dimension by the entropic process which encapsulates diversity of a data population space (the same author's "Noah's Effect"), are the conceptual foundations of this analytical framework. 
The basic paradigm of the model is based on an assumption that the investors' risk/return assessment is the product of comprehensive expectations concerning the total risk. In other words, such approach is conceptually synthetic, not for example considering any perhaps questionable distinction between the "risk-free" rate and the "risk premium", on the one hand, and the "residual" risk versus the so called market-driven "systematic risk", on the other hand. Market participants" behaviour is certainly complex and determined by a number of different causes, including emotional conditions of the market participants, seasonal factors, new emerging investment opportunities, economic/political fundamentals, etc., generating the market price continuity as well as volatility, and therefore investors seem to be rather prone to base their decisions on a consideration of perceived full investment risk.

Conceptually, the model is represented by the two key variables with a complementary variable representing an autocorrelation extension of the dependent variable, i.e.:

$$
\begin{aligned}
\hat{R}(m / j, p)= & \{\eta(m / j)+\varepsilon(m / j, p)\}+\rho(m / j) \cdot \Delta V I X(t)+ \\
& +\left\{\sum_{k=1}^{n} \varphi(m / j, k) \cdot R(m / j, p-k)\right\},
\end{aligned}
$$

for $p=(t+30)$ days, and $k=1, \ldots, n$ months,

where $R(m / j, p)=$ the dependent variable, expected return representing market index return $R(m, p)$, or a security $j$ return $R(j, p)$ in time $p$ days, i.e. the percentage price change $P(m / j, p) / P(m / j, t)$, determined on the daily moving basis;

$\eta(m / j)=$ the expected constant component of the return $R(\mathrm{~m} / \mathrm{j}, \mathrm{p})$, representing an average effect of the past returns as a continuity of serial dependence;

$\varepsilon(\mathrm{m} / \mathrm{j}, \mathrm{p})=$ a random dispersion of the expected part of the return's serial dependence $\eta(\mathrm{m} / \mathrm{j})$;

$\Delta V I X(t)=$ is the independent variable as a 30 day percentage change of the VIX Index in time $t$ reflecting the volatility of the S\&P 500 market index in the period 30 days hence, i.e. $\Delta V I X(t)=V I X(t) / V I X(t-30)$; $\rho(m / j)=$ the sensitivity coefficient of the expected return $R(j, p)$ to a change in the market volatility expectations (i.e. $\triangle V I X)$; 


$$
\begin{aligned}
R(m / j, p-k)= & \text { the market index } \mathrm{S} \& \mathrm{P} 500, \text { or a selected security's } \\
& 30 \text { day return, lagged in the specified past period } \\
& \text { on the daily moving basis; } \\
\phi(m / j, k)= & \text { the sensitivity coefficient of the expected return } \\
& R(m / j, p) \text { on the lagged returns } R(m, p-k) \text { in the past } \\
& n=(p-k) \text { periods; the independent variable series } \\
& \text { complementary to the constant } \eta(m / j) \text { applicable } \\
& \text { to the extended model as an expression of variable } \\
& \text { serial dependence, determined on the daily } \\
& \text { moving basis for total } n \text { monthly periods. }
\end{aligned}
$$

\subsection{Methodology}

The VIX Index, the independent variable, selected to express the model's volatility component also known as "indicator of fear", has generally a broad inverse relationship to the underlying market index S\&P 500. In other words, when the market index is rising index VIX is typically falling and vice versa, and this is expressed as a point deviation from the expected market index average, thus capturing its envisaged volatility. The VIX's construction uses near-term and next-term out-of the money SPX options with at least 8 days left to expiration and then weights them to yield a constant 30 day measure of the expected volatility of the S\&P Index. It is therefore an expectation type of indicator as oppose to a typical ex post indicator such as the market index itself. When it is reaching very high values (e.g. above 30 or 35 points) it then indicates that the "bearish" fear and panic of the market have reached probably the maximum and the market is in a trough, but with a possible outlook that soon there can be a turnaround in the form of a rising trend.

On the contrary, when VIX Index hovers around its minimum level (e.g. around 10 points) the market is complacent, but a next storm can be around the corner.

Therefore broadly speaking: "if VIX is high, it's time to buy, if VIX is low, it's time to go"! In fact, the index practically measures the cost of equity insurance as a proxy for Wall Street fear and it is therefore a natural hedge for equity risk exposure.

The expected risk profile, e.g. for a security $j$ can be in the framework of this model expressed as: 


$$
p(j)^{2} \cdot \sigma^{2}(V I X)+\sum_{k=1}^{n} \varphi(j, k)^{2} \cdot \sigma^{2} \cdot R(m, p-k)+\eta^{2}(j) \cdot \sigma^{2} \cdot \varepsilon(j)
$$

where the first terms reflects a dispersion of the expected volatility index, being followed by the ex post dispersion of the lagged market index and the third term features the random dispersion of the expected constant component of the continuity of the past return's serial dependence.

The model's expected return is therefore a function of the anticipated volatility of the market performance $\rho$ and the non-volatility-induced part representing the expected constant continuity of the past performance $\eta$, with its dispersion factor $\varepsilon$, together with the lagged independent component representing the variable part of the serial dependence and expressed by coefficient $\phi$.

As far as the portfolio selection is concerned, because the notion of the "risk-free" return or a "residual risk" as such is not considered, this process cannot be based only on the category of the so called "excess return". It would involve optimizing the appropriate correlation matrix reflecting the total risk of individual securities assembled in the portfolio according to the Markowitz's mean-variance maximization concept. On the other hand, when the return on the whole market performance is considered, the process of market index portfolio selection would need to take place across several security markets, in order for the index aggregate variance to be optimized.

To test the model outlined above, the simple/multiple linear regression routine was applied, where in the first instance, the changes in the volatility index VIX was selected as the independent variable. The regression coefficient $\rho$ then represents a percentage degree of responsiveness of the actual return's volatility, i.e. of the market index S\&P500 (or a security return), being the dependent variables, to a percentage change in volatility expectations expressed by the VIX Index, thus measuring a sensitivity of these returns to such expectations.

The total "market memory" factor can be therefore expressed as:

$$
\{\eta(m / j)+\varepsilon(m / j, p)\}+\left\{\sum_{k=1}^{n} \varphi(m / j, k) \cdot \hat{R}(m / j, p-k)\right\},
$$

for $j$ and $k$ determined per above outline. 
The described view of course contrasts with the usual interpretation of the coefficients $\alpha$ and $\beta$ related to the "standard" models, e.g. the SIM, where the perception of the risk is typically divided into the $\alpha$-based, "nonmarket-induced" factor with its corresponding residual $e$, and the $\beta$ related factor to be strictly a reflection of the so called "marketassociated" component of the risk.

Generally it is assumed that using various information inputs, the market participants when deciding on the market performance form their investment attitudes as then expressed by the combination of the call/put option values placed on the market index, whilst also considering the past interacting trend of security prices and their returns. The associated risk is therefore viewed as a single, homogeneous category based on these two factors.

The Coefficient of Determination $R^{2}$ used in this model as one of the evaluation criteria reflects an extent to which the volatility expectations concerning the market and the lagged factors determine the actual ex post performance outcome of either the market or a security return.

To assess a significance of the complementary autocorrelated lags influencing the corresponding returns, the regression residuals were tested using the Box-Jenkins method when all values of residuals' autocorrelation and partial autocorrelation (up to 12 lags) functions remained within the 95\% confidence level interval, thus proved to be near zero with only four single peaks of no significant pattern, (refer to Tab. 1). This results indicate that no further explanatory factor beyond one lagged period would need to apply.

Tab. 1: Residuals' autocorrelation significance

\begin{tabular}{|l|l|l|l|}
\hline Period & $\begin{array}{c}\text { Residual } \\
\text { correlation } \\
\text { significant }\end{array}$ & $\begin{array}{c}\text { Significant lags } \\
\text { number }\end{array}$ & $\begin{array}{c}\text { ACF Significant } \\
\text { lags number } \\
\text { PACF }\end{array}$ \\
\hline $1 / 2005$ & no & - & \\
\hline $2 / 2005$ & no & - & \\
\hline $3 / 2005$ & no & - & 3 \\
\hline $4 / 2005$ & yes & 4 & 6 \\
\hline $5 / 2005$ & yes & 9 & \\
\hline $6 / 2005$ & no & - & - \\
\hline $7 / 2005$ & no & - & \\
\hline
\end{tabular}




\begin{tabular}{|l|l|l|l|}
\hline Period & $\begin{array}{c}\text { Residual } \\
\text { correlation } \\
\text { significant }\end{array}$ & \multicolumn{1}{|c|}{$\begin{array}{c}\text { Significant lags } \\
\text { number }\end{array}$} & $\begin{array}{c}\text { ACF Significant } \\
\text { lags number } \\
\text { PACF }\end{array}$ \\
\hline $8 / 2005$ & no & - & - \\
\hline $9 / 2005$ & no & - & - \\
\hline $10 / 2005$ & no & - & - \\
\hline $11 / 2005$ & no & - & - \\
\hline $12 / 2005$ & yes & $4,5,9$ & 4,5 \\
\hline $1 / 2008$ & no & - & \\
\hline $2 / 2008$ & no & - & \\
\hline $3 / 2008$ & no & - & \\
\hline $4 / 2008$ & no & - & 6 \\
\hline $5 / 2008$ & yes & - & \\
\hline $6 / 2008$ & no & - & \\
\hline $7 / 2008$ & no & - & \\
\hline $8 / 2008$ & no & - & \\
\hline $9 / 2008$ & no & - & \\
\hline $10 / 2008$ & no & - & \\
\hline $11 / 2008$ & no & - & \\
\hline $12 / 2008$ & no & - & \\
\hline
\end{tabular}

Following that, the autocorrelation of the lagged variable $\phi$ was also tested for two periods under the test to ascertain its actual explanatory significance in terms of the serial $R^{2}$ and the $R^{2}$ adjusted for pair correlations. The latter indicator confirmed the sufficient explanatory value of $\phi$ in one lag for both periods, $96.4 \%$ and $98.2 \%$, respectively, (refer to Tab. 2 and 3).

Tab. 2: Autocorrelation assessment, variable $\varphi$, First Tier $1^{\text {st }}$ January $2005-31^{\text {st }}$ December 2005, included observations: 260)

\begin{tabular}{|l|l|l|l|l|r|r|r|}
\hline Autocorrelation & \multicolumn{2}{|c|}{$\begin{array}{c}\text { Partial } \\
\text { Correlation }\end{array}$} & & AC & PAC & Q-Stat & Prob \\
\hline.$\left.\right|^{*} * * * * *$ &. $\mid * * * * * *$ & 1 & 0.964 & 0.964 & 244.24 & 0.000 \\
\hline.$\left.\right|^{*} * * * * *$ &. $\mid$. & 2 & 0.933 & 0.057 & 473.90 & 0.000 \\
\hline.$|* * * * *|$ &. $\mid$ & & 3 & 0.901 & -0.020 & 689.07 & 0.000 \\
\hline.$|* * * * * *|$ &. $\mid$ & & 4 & 0.873 & 0.029 & 891.69 & 0.000 \\
\hline
\end{tabular}


Kuklik, R. G. - Vacek, V.: Volatility Asset Pricing Model as an Alternative Approach?

\begin{tabular}{|c|c|c|c|c|c|c|}
\hline \multirow{2}{*}{$\begin{array}{l}\text { Autocorrelation } \\
||_{* * * * * \mid}\end{array}$} & $\begin{array}{c}\text { Partial } \\
\text { Correlation }\end{array}$ & \multirow{2}{*}{\multicolumn{2}{|c|}{\begin{tabular}{c|c} 
& AC \\
5 & 0.842
\end{tabular}}} & \multirow{2}{*}{$\begin{array}{l}\text { PAC } \\
-0.044\end{array}$} & \multirow{2}{*}{$\begin{array}{c}\text { Q-Stat } \\
1081.0\end{array}$} & \multirow{2}{*}{$\begin{array}{l}\text { Prob } \\
0.000\end{array}$} \\
\hline & .1. & & & & & \\
\hline . $* * * * * *$ & $*$. & 6 & 0.808 & -0.068 & 1255.8 & 0.000 \\
\hline ******* & .1. & 7 & 0.776 & 0.015 & 1418.0 & 0.000 \\
\hline$. * * * * * \mid$ &. & 8 & 0.748 & 0.026 & 1569.1 & 0.000 \\
\hline$|* * * * *|$ & .1. & 9 & 0.717 & -0.037 & 1708.7 & 0.000 \\
\hline$|* * * * *|$ & .1. & 10 & 0.687 & -0.015 & 1837.3 & 0.000 \\
\hline $\mid * * * * *$ & .1. & 11 & 0.655 & -0.037 & 1954.8 & 0.000 \\
\hline$|* * * * *|$ & .1. & 12 & 0.625 & -0.006 & 2062.2 & 0.000 \\
\hline **** & .1 & 13 & 0.597 & 0.013 & 2160.5 & 0.000 \\
\hline ***** & .1. & 14 & 0.569 & -0.011 & 2250.2 & 0.000 \\
\hline . $* * * *$ & .1. & 15 & 0.540 & -0.029 & 2331.2 & 0.000 \\
\hline $\mid * * * *$ & .1. & 16 & 0.514 & 0.031 & 2405.1 & 0.000 \\
\hline . $* * * *$ & $*$. & 17 & 0.485 & -0.070 & 2471.1 & 0.000 \\
\hline $.1 * * *$ & .1. & 18 & 0.456 & -0.032 & 2529.5 & 0.000 \\
\hline $.1 * * *$ & .1. & 19 & 0.426 & -0.022 & 2580.7 & 0.000 \\
\hline $.1 * * *$ & .1. & 20 & 0.394 & -0.046 & 2624.8 & 0.000 \\
\hline . $* * *$ & .1 & 21 & 0.365 & -0.002 & 2662.7 & 0.000 \\
\hline.$* *$ & $* 1$. & 22 & 0.330 & -0.085 & 2693.8 & 0.000 \\
\hline $.1^{* *}$ & .1. & 23 & 0.297 & -0.003 & 2719.2 & 0.000 \\
\hline $.1 * *$ & .1. & 24 & 0.267 & 0.009 & 2739.8 & 0.000 \\
\hline $.1^{* *}$ & .1. & 25 & 0.238 & -0.004 & 2756.3 & 0.000 \\
\hline.$I^{*}$ & .1 & 26 & 0.210 & -0.014 & 2769.1 & 0.000 \\
\hline $.1^{*}$ & .1. & 27 & 0.186 & 0.057 & 2779.2 & 0.000 \\
\hline $.1^{*}$ & .1. & 28 & 0.166 & 0.049 & 2787.3 & 0.000 \\
\hline $.1^{*}$ & .1. & 29 & 0.148 & -0.003 & 2793.8 & 0.000 \\
\hline $.1^{*}$ & .1. & 30 & 0.133 & 0.039 & 2799.0 & 0.000 \\
\hline $.1^{*}$ & .1. & 31 & 0.120 & 0.030 & 2803.3 & 0.000 \\
\hline $.1^{*}$ & .1. & 32 & 0.110 & 0.019 & 2807.0 & 0.000 \\
\hline.$*$ & .1. & 33 & 0.105 & 0.064 & 2810.3 & 0.000 \\
\hline.$*$ & $.1^{*}$ & 34 & 0.105 & 0.077 & 2813.6 & 0.000 \\
\hline $.1^{*}$ & *1. & 35 & 0.098 & -0.090 & 2816.5 & 0.000 \\
\hline 1 & $\begin{array}{l}.1 \\
\end{array}$ & 36 & 0.092 & -0.001 & 2819.1 & 0.000 \\
\hline
\end{tabular}

Note: $A C=$ value of the $R^{2}$ for a serial position $t$ and $t-k$, (a number in the column); $A C=$ partial correlation, $A C$ between $t$ and $t-k$, when the effect of all values $t-1 \ldots t(k-$ 1) was eliminated; Falling $A C$ and only the first $P A C$ being significantly of a non-zero value shows the first lag to be only significant and therefore relevant for applying the 
complementary variable $\phi$ in the extended model (resulting data denominated $A R$ in the relevant tables).

Tab. 3: Autocorrelation assessment, variable $\varphi$, Second Tier $1^{\text {st }}$ January $2008-31^{\text {st }}$ December 2008, included observations: 262)

\begin{tabular}{|c|c|c|c|c|c|c|}
\hline Autocorrelation & $\begin{array}{r}\mathbf{P} \\
\text { Cor }\end{array}$ & & $\mathbf{A C}$ & PAC & Q-Stat & Prob \\
\hline. $\mid * * * * * * *$ & $\left.\right|^{* *}$ & 1 & 0.982 & 0.982 & 255.58 & 0.000 \\
\hline . $* * * * * * *$ &.$*$ & 2 & 0.967 & 0.081 & 504.50 & 0.000 \\
\hline. $\mid * * * * * * *$ & .1. & 3 & 0.954 & 0.054 & 747.77 & 0.000 \\
\hline . $* * * * * * *$ & .1. & 4 & 0.941 & -0.022 & 985.00 & 0.000 \\
\hline . $* * * * * * *$ & .1. & 5 & 0.927 & 0.008 & 1216.5 & 0.000 \\
\hline . $* * * * * * *$ & .1. & 6 & 0.915 & 0.006 & 1442.6 & 0.000 \\
\hline . $* * * * * * *$ & .1. & 7 & 0.902 & 0.007 & 1663.4 & 0.000 \\
\hline$|* * * * * *|$ & .1. & 8 & 0.890 & 0.009 & 1879.2 & 0.000 \\
\hline$|* * * * * *|$ & .1. & 9 & 0.877 & -0.046 & 2089.3 & 0.000 \\
\hline$|* * * * * *|$ & .1. & 10 & 0.864 & -0.002 & 2294.0 & 0.000 \\
\hline$|* * * * * *|$ & .1. & 11 & 0.851 & 0.003 & 2493.5 & 0.000 \\
\hline$|* * * * * *|$ & .1. & 12 & 0.838 & -0.015 & 2687.7 & 0.000 \\
\hline $\mid * * * * * *$ & .1. & 13 & 0.825 & -0.000 & 2876.7 & 0.000 \\
\hline.$|* * * * * *|$ & .1. & 14 & 0.812 & -0.011 & 3060.6 & 0.000 \\
\hline$|* * * * * *|$ & .1. & 15 & 0.799 & -0.006 & 3239.3 & 0.000 \\
\hline$|* * * * * *|$ &.$*$ & 16 & 0.789 & 0.087 & 3414.6 & 0.000 \\
\hline$. * * * * * * \mid$ & $* 1$. & 17 & 0.777 & -0.073 & 3584.9 & 0.000 \\
\hline$. * * * * * * \mid$ & .1. & 18 & 0.762 & -0.063 & 3749.7 & 0.000 \\
\hline . $* * * * *$ & .1. & 19 & 0.750 & 0.029 & 3909.8 & 0.000 \\
\hline . $* * * * *$ & .1. & 20 & 0.736 & -0.036 & 4064.8 & 0.000 \\
\hline $\mid * * * * *$ & .1. & 21 & 0.721 & -0.062 & 4213.8 & 0.000 \\
\hline . $* * * * *$ & .1. & 22 & 0.706 & -0.010 & 4357.3 & 0.000 \\
\hline . $* * * * *$ & $* 1$. & 23 & 0.688 & -0.070 & 4494.5 & 0.000 \\
\hline ****** & .1. & 24 & 0.673 & 0.026 & 4626.2 & 0.000 \\
\hline . $* * * * *$ & .1. & 25 & 0.659 & 0.028 & 4753.0 & 0.000 \\
\hline . $* * * * *$ & .1. & 26 & 0.645 & 0.004 & 4874.8 & 0.000 \\
\hline . $* * * * *$ & .1. & 27 & 0.629 & -0.063 & 4991.2 & 0.000 \\
\hline . $* * * *$ & .1. & 28 & 0.613 & -0.012 & 5102.3 & 0.000 \\
\hline . $* * * *$ & $* 1$. & 29 & 0.595 & -0.069 & 5207.5 & 0.000 \\
\hline . $* * * *$ & $* 1$. & 30 & 0.575 & -0.103 & 5306.1 & 0.000 \\
\hline . $* * * *$ & .1. & 31 & 0.555 & 0.003 & 5398.4 & 0.000 \\
\hline
\end{tabular}




\begin{tabular}{|c|c|c|c|c|c|c|c|}
\hline \multicolumn{2}{|c|}{ Autocorrelation } & \multicolumn{2}{|c|}{$\begin{array}{c}\text { Partial } \\
\text { Correlation }\end{array}$} & \multirow{2}{*}{$\begin{array}{l}\mathbf{A C} \\
0.538\end{array}$} & \multirow{2}{*}{$\begin{array}{r}\text { PAC } \\
0.023\end{array}$} & \multirow{2}{*}{$\begin{array}{r}\text { Q-Stat } \\
5485.3\end{array}$} & \multirow{2}{*}{$\begin{array}{r}\text { Prob } \\
0.000\end{array}$} \\
\hline . $* * * *$ & & .1 & & & & & \\
\hline . $* * * *$ & & .1. & & 0.519 & -0.028 & 5566.7 & 0.000 \\
\hline . $* * * *$ & & .1 & & 0.501 & -0.011 & 5642.7 & 0.000 \\
\hline$* * * *$ & & .1. & & 0.485 & 0.063 & 5714.3 & 0.000 \\
\hline | $* * *$ & & .1. & & 0.469 & -0.020 & 5781.6 & 0.000 \\
\hline
\end{tabular}

Further to that, the Durbin-Watson Statistics was derived in order to assess, in conjunction with the Standard Error of Estimate, the significance of residual terms concerning the serial dependence. Also the short-term prediction accuracy of the model was appraised by using computation of the Mean Absolute Percentage Estimated Error (EER) of the following month forecast. In addition, for the sampled companies as a matter of comparison the "classical" Single Index Model was applied producing the corresponding coefficients $\alpha$ and $\beta$ for selected periods in the standard fashion.

In this context, considering the VAPM framework, the coefficients $(\eta+\varepsilon), \rho$ and $\phi$ representing the market price structure, i.e. the volatility as well as the serial dependence, in fact embody in toto the corresponding structure of the SIM, i.e. $\alpha, \beta$ and $e$, here representing the so called "market" as well as the "non-market-induced" returns, respectively.

\subsection{The Model's Testing, Results and Interpretations}

The tests were performed in two Parts on the daily moving basis.

3.3.1 In Part I the relationship S\&P500/VIX Index was tested in two separate periods:

The First Tier - 12 months between 1. 1. 2005 and 31. 12. 2005, covering 260 observations on the daily basis in the period of relative market stability, and

The Second Tier - 12 months between 1. 1. 2008 and 31. 12. 2008 encompassing 262 observations on the daily basis, and divided in two parts i.e. January - August, prior to the market meltdown, and September - December for the rest of the year.

The model was applied in two methodological Modes: 
- Mode A: the basic model's version with the variables, dependent S\&P500 Index, and coefficients $\eta$, representing the constant part of serial dependence, and $\rho$, the coefficient reflecting the sensitivity of the market index regarding the independent variable VIX Index;

- Mode B: the model's basic version was, as outlined above, extended for a consideration of the additional variable $(\phi)$ representing the serial dependence, on the index return lagged basis, i.e. the variable "market memory", thus complementing the serial dependence constant $\eta$.

3.3.1.1 The First Tier of the market index test (Jan-Dec 2005), was concerned with performance of the S\&P 500 and VIX indices shown in Fig. 2, indicates for Mode A, a range of the Coefficient of Determination $\mathrm{R}^{2}$ as $2 \%-79 \%$ with the average value $33 \%$, and the average $68 \%$ falling into the range $9 \%-90 \%$ in the case of Mode B. Both peak values of corresponding ranges are attainable at $95 \%$ confidence level, assuming the $t$-distribution, (refer to Tab. 4). The constant coefficient $\eta$ shows the averages 0.95 and 0.22 , respectively. This relative difference is compensated by the effect of the complementary variable causing the increase of $\mathrm{R}^{2}$, with the independent variable $(\rho)$, as the sensitivity measure of volatility, resulting approximately the same, 0.08 and 0.06 in average. The Standard Error of Estimate shows a practically identical value for both Modes (0.01). The $D-W$ statistic when comparing both models shows the values 0.65 and 1.98 for the Mode $A$ and Mode B, respectively. A substantially lower serial correlation of residuals of the latter indicates the complementary role of the additional variable. This effect is also reflected in a decline in the short-term forecast expected error EER from $2.45 \%$ to $0.95 \%$. The summary of average results is shown in the Tab. 5.

Tab. 4: Results of the sample test S\&P500/VIX, First Tier (Jan - Dec 2005); (Results of the extended model Mode $B$ are designated AR)

\begin{tabular}{|r|c|c|c|c|r|r|r|}
\hline & $\mathbf{R}^{2}$ & $\boldsymbol{\eta}$ & $\boldsymbol{\rho}$ & $\boldsymbol{\varphi}$ & \multicolumn{1}{c|}{ SEE } & \multicolumn{1}{c|}{ EER } & \multicolumn{1}{c|}{ DW } \\
\hline $1 / 2005$ & 0.385 & 0.891 & 0.125 & & 0.011 & 2.199 & 0.422 \\
\hline $\mathrm{AR}$ & 0.782 & 0.896 & 0.122 & 0.752 & 0.007 & 0.847 & 1.893 \\
\hline $2 / 2005$ & 0.587 & 0.890 & 0.101 & & 0.007 & 2.526 & 1.117 \\
\hline $\mathrm{AR}$ & 0.704 & 0.904 & 0.085 & 0.451 & 0.006 & 1.343 & 2.297 \\
\hline
\end{tabular}


Kuklik, R. G. - Vacek, V.: Volatility Asset Pricing Model as an Alternative Approach?

\begin{tabular}{|r|r|r|r|r|r|r|r|}
\hline $3 / 2005$ & 0.724 & 0.831 & 0.133 & & 0.012 & 3.709 & 0.670 \\
\hline $\mathrm{AR}$ & 0.859 & 0.851 & 0.112 & 0.685 & 0.009 & 1.571 & 1.974 \\
\hline $4 / 2005$ & 0.283 & 0.919 & 0.090 & & 0.019 & 1.626 & 0.237 \\
\hline $\mathrm{AR}$ & 0.896 & 0.964 & 0.063 & 0.841 & 0.007 & 0.572 & 2.643 \\
\hline $5 / 2005$ & 0.082 & 0.989 & 0.033 & & 0.014 & 0.991 & 0.295 \\
\hline $\mathrm{AR}$ & 0.758 & 1.004 & 0.016 & 0.851 & 0.007 & 0.493 & 2.083 \\
\hline $6 / 2005$ & 0.056 & 1.001 & 0.029 & & 0.006 & 2.766 & 1.447 \\
\hline $\mathrm{AR}$ & 0.094 & 0.998 & 0.034 & 0.224 & 0.006 & 2.285 & 1.786 \\
\hline $7 / 2005$ & 0.137 & 0.911 & 0.098 & & 0.014 & 3.182 & 0.416 \\
\hline $\mathrm{AR}$ & 0.758 & 0.935 & 0.066 & 0.729 & 0.008 & 0.938 & 2.708 \\
\hline $8 / 2005$ & 0.118 & 1.035 & -0.038 & & 0.011 & 1.963 & 0.859 \\
\hline $\mathrm{AR}$ & 0.456 & 0.929 & 0.043 & 0.866 & 0.009 & 0.753 & 1.313 \\
\hline $9 / 2005$ & 0.169 & 1.051 & -0.066 & & 0.018 & 7.460 & 0.488 \\
\hline $\mathrm{AR}$ & 0.808 & 0.981 & 0.048 & 0.952 & 0.009 & 0.760 & 2.423 \\
\hline $10 / 200$ & & & & & & & \\
5 & 0.583 & 0.901 & 0.131 & & 0.013 & 0.879 & 0.544 \\
\hline $\mathrm{AR}$ & 0.817 & 0.944 & 0.094 & 0.759 & 0.009 & 0.436 & 1.890 \\
\hline $11 / 200$ & & & & & & & \\
5 & 0.788 & 0.940 & 0.096 & & 0.007 & 1.477 & 0.641 \\
\hline $\mathrm{AR}$ & 0.861 & 0.953 & 0.083 & 0.619 & 0.006 & 0.802 & 0.973 \\
\hline $12 / 200$ & & & & & & & \\
\hline 5 & 0.018 & 1.020 & -0.013 & & 0.009 & 0.647 & 0.672 \\
\hline $\mathrm{AR}$ & 0.427 & 0.998 & 0.012 & 0.579 & 0.007 & 0.553 & 1.721 \\
\hline
\end{tabular}

Tab. 5: Summary of the average results, sample test S\&P/VIX Index First Tier (Jan - Dec 2005)

\begin{tabular}{|l|l|l|l|l|l|l|}
\hline Parameter & $\mathbf{R}^{\mathbf{2}}$ & $\boldsymbol{\eta}$ & $\boldsymbol{\rho}$ & $\boldsymbol{\varphi}$ & $\mathbf{D - W}$ & EER \\
\hline Jan - Dec Mode A & 0.33 & 0.95 & 0.08 & -- & 0.65 & 2.45 \\
\hline Jan - Dec Mode B & 0.68 & 0.22 & 0.06 & 0.69 & 1.98 & 0.95 \\
\hline
\end{tabular}

3.3.1.2 The Second Tier of the market index test on sensitivity S\&P500/VIX Index involved the application of both model's Modes in the period January-December 2008, subsequently divided in two parts, as outlined above. 
The results in the whole period tested indicate for the basic Mode $A$ the coefficient $\mathrm{R}^{2}$ in the interval $4 \%-77 \%$ with the average $37 \%$, and for the Mode B, the extended version, $9 \%-83 \%$ with the average $66 \%$. However, here only for the Mode $B$ is the peak value of the quoted range attainable at $95 \%$ confidence level of the $t$ distribution. This difference shows again the increased correlation effect of the additional variable representing the supplementary factor of the serial dependence.

The D-W statistic varies in the range $0.43-1.83$, where with the average 0.87 it shows a stronger correlation of residuals $\varepsilon$ indicating an implied serial dependence for the basic model, as oppose to the range $1.51-2.53$, with the average 2.03 for the extended model. The influence of the non-volatility-induced factor had been likely taken up by the additional variable, with the volatility coefficient $\rho$ declining in average from 0.15 to 0.9 whilst the expected serial dependence constant $\eta$ remaining approximately even (0.86 and 0.90 , respectively).

The EER indicator concerning the model's predictive accuracy stands more in favour of the extended version with the range $2.1 \%-38.3 \%$ and average $10.0 \%$, if compared with the range $1.3 \%-50.5 \%$ and average $13.6 \%$ for the basic model, thus offering a stronger explanatory power, (refer to Tab. 6).

\section{Tab. 6: Results of the sample test S\&P500/VIX Index Second Tier (Jan - Dec 2008); (Results of the extended model, Mode $B$ are designated AR)}

\begin{tabular}{|l|r|r|r|r|r|r|r|}
\hline \multicolumn{1}{|c|}{ Period } & $\mathbf{R}^{\mathbf{2}}$ & \multicolumn{1}{c|}{$\boldsymbol{\eta}$} & \multicolumn{1}{c|}{$\boldsymbol{\rho}$} & \multicolumn{1}{c|}{$\boldsymbol{\varphi}$} & \multicolumn{1}{c|}{ SEE } & \multicolumn{1}{c|}{ EER } & \multicolumn{1}{c|}{ DW } \\
\hline 1.1 .2008 & 0.418 & 0.859 & 0.102 & & 0.022 & 3.319 & 0.531 \\
\hline $1 / 2008 \mathrm{AR}$ & 0.732 & 0.858 & 0.103 & 0.734 & 0.015 & 1.684 & 1.910 \\
\hline 1.2 .2008 & 0.122 & 1.038 & -0.043 & & 0.024 & 5.433 & 0.854 \\
\hline $2 / 2008 \mathrm{AR}$ & 0.411 & 0.994 & -0.001 & 0.617 & 0.020 & 2.598 & 1.873 \\
\hline 1.3 .2008 & 0.482 & 0.896 & 0.156 & & 0.018 & 1.330 & 0.887 \\
\hline $3 / 2008 \mathrm{AR}$ & 0.705 & 0.928 & 0.128 & 0.578 & 0.014 & 1.218 & 2.127 \\
\hline 1.4 .2008 & 0.700 & 0.876 & 0.166 & & 0.014 & 8.785 & 0.874 \\
\hline $4 / 2008 \mathrm{AR}$ & 0.793 & 0.914 & 0.111 & 0.735 & 0.012 & 2.587 & 1.990 \\
\hline 1.5 .2008 & 0.397 & 1.114 & -0.242 & & 0.021 & 11.21 & 0.697 \\
\hline $5 / 2008 \mathrm{AR}$ & 0.808 & 0.811 & 0.067 & 0.937 & 0.012 & 1.514 & 2.467 \\
\hline
\end{tabular}


Kuklik, R. G. - Vacek, V.: Volatility Asset Pricing Model as an Alternative Approach?

\begin{tabular}{|l|r|r|r|r|r|r|r|}
\hline \multicolumn{1}{|c|}{ Period } & $\mathbf{R}^{\mathbf{2}}$ & \multicolumn{1}{c|}{$\boldsymbol{\eta}$} & $\boldsymbol{\rho}$ & \multicolumn{1}{c|}{$\boldsymbol{\varphi}$} & \multicolumn{1}{c|}{ SEE } & \multicolumn{1}{c|}{ EER } & \multicolumn{1}{c|}{ DW } \\
\hline 1.6 .2008 & 0.765 & 0.668 & 0.234 & & 0.019 & 6.143 & 1.825 \\
\hline $6 / 2008 \mathrm{AR}$ & 0.766 & 0.674 & 0.229 & 0.060 & 0.019 & 5.794 & 1.851 \\
\hline 1.7 .2008 & 0.521 & 0.908 & 0.086 & & 0.016 & 11.537 & 1.079 \\
\hline $7 / 2008 \mathrm{AR}$ & 0.620 & 0.895 & 0.097 & 0.470 & 0.015 & 7.131 & 2.076 \\
\hline 1.8 .2008 & 0.302 & 0.454 & 0.508 & & 0.072 & 50.499 & 0.432 \\
\hline $8 / 2008 \mathrm{AR}$ & 0.834 & 1.565 & 0.016 & 1.020 & 0.036 & 4.845 & 2.533 \\
\hline 1.9 .2008 & 0.306 & 0.691 & 0.056 & & 0.032 & 28.042 & 1.252 \\
\hline $9 / 2008 \mathrm{AR}$ & 0.346 & 0.688 & 0.059 & 0.237 & 0.032 & 6.688 & 1.513 \\
\hline 1.10 .2008 & 0.040 & 0.805 & 0.035 & & 0.080 & 14.845 & 0.550 \\
\hline $10 / 2008 \mathrm{AR}$ & 0.592 & 0.705 & 0.082 & 0.784 & 0.053 & 4.933 & 2.444 \\
\hline 1.11 .2008 & 0.146 & 1.150 & -0.102 & & 0.077 & 11.214 & 0.620 \\
\hline $11 / 2008 \mathrm{AR}$ & 0.783 & 0.948 & 0.099 & 0.864 & 0.040 & 2.490 & 1.638 \\
\hline 1.12 .2008 & 0.222 & 0.886 & 0.092 & & 0.033 & 10.413 & 0.848 \\
\hline $12 / 2008 \mathrm{AR}$ & 0.478 & 0.875 & 0.101 & 0.563 & 0.028 & 4.790 & 1.929 \\
\hline
\end{tabular}

3.3.2 Further, the testing routine of the Second Tier the market index test encompasses the two sub-periods, i.e. 8 months. January-August 2008 , prior to the stock market crash commencing on the $15_{\text {th }}$ September and remaining period of the year, i.e. 4 months. September-December 2008.

The first sub-period shows for the Mode A, the basic model, the Coefficient of Determination $\mathrm{R}^{2}$ smaller in average (46\%) than in the case of Mode B, the extended model $(71 \%)$. The higher level of correlation concerning the latter can be explained by a complementary effect of the additional variable. The larger coefficient $\eta$ (0.95 versus 0.85$)$ shows a stronger influence of the constant component of the serial dependence regarding the extended model but in lieu of a lower level of the S\&P500 Index' responsiveness $\rho$ to a change in the VIX Index $(0.09$ versus $0.12)$.

The comparison with the second sub-period highlights a decline in the coefficient $\rho$ for the Mode A. indicating a lower level of accuracy concerning the estimates of the expected market index volatility which can essentially explain a sharp decline in $\mathrm{R}^{2}$ (from 0.46 to 0.18 ) in the case of the basic model. This occurs in line with the fall in the D-W statistic for both models. Mode $A$ and $B$ (0.92 to 0.82 and 2.1 to 1.88 . 
respectively).This development can be attributed to the unexpected stock market sharp fall.

As far as the Mode $B$ is concerned the fall of $\mathrm{R}^{2}$ (from 0.71 to 0.55 ) can be possibly also related to a significant decline of the underlying serial dependence factor $\eta$. (from 0.95 to 0.80) suggesting a strong incidence of discontinuity of the price series whilst the sensitivity shown by the variable component of serial dependence remained approximately unchanged for both sub-periods.

Performance of the Standard Error of Estimate appears to be even for both Modes in both sub-periods. The EER indicator on the other hand stands distinctly in favour of the Mode $B$ in both sub-periods with substantially lower forecasting percentage errors. The summary of average results indicates Tab. 7 .

Tab. 7: Summary of average results, sample test S\&P500/VIX Index, Second Tier (Jan - Aug and Sept - Dec 2008)

\begin{tabular}{|l|l|l|l|l|l|l|l|}
\hline Parameter & $\mathrm{R}^{2}$ & $\eta$ & $\rho$ & $\phi$ & SEE & $\mathrm{D}-\mathrm{W}$ & EER \% \\
\hline Jan-Aug Mode A & 0.46 & 0.85 & 0.12 & - & 0.03 & 0.92 & 12.35 \\
\hline Sept-Dec Mode A & 0.18 & 0.88 & 0.02 & - & 0.06 & 0.82 & 16.10 \\
\hline Jan-Aug Mode B & 0.71 & 0.95 & 0.09 & 0.64 & 0.02 & 2.10 & 3.42 \\
\hline Sept-Dec Mode B & 0.55 & 0.80 & 0.09 & 0.61 & 0.04 & 1.88 & 4.73 \\
\hline
\end{tabular}

When comparing results of both model's versions in both time subperiods it is possible to observe the impact of the additional variable $\phi$ manifesting itself in the rise of $\mathrm{R}^{2}$ and a shock caused by the stockmarket meltdown.

3.4 The Part II of the VAPM framework testing involved a sample of returns of 10 prime selected companies listed on the NYSE for their sensitivity concerning the VIX Index as well as the lagged serial dependence on the past returns (refer to Tab. 8). 
Kuklik, R. G. - Vacek, V.: Volatility Asset Pricing Model as an Alternative Approach?

Tab. 8: Performance of securities' return /VIX index May 2005 \& September 2008; (Mode B application marked with asterix)

\begin{tabular}{|l|l|r|r|r|r|r|r|r|}
\hline Company & Period & \multicolumn{1}{|c|}{$\mathbf{2}$} & \multicolumn{1}{|c|}{$\boldsymbol{\eta}$} & \multicolumn{1}{|c|}{ P } & $\boldsymbol{\varphi}$ & SEE & EER\% & DW \\
\hline Exxon & $5 / 2005$ & 0,03 & 1,02 & 0,04 & & 0,03 & 3,84 & 0,58 \\
\hline & $*$ & 0,58 & 0,98 & 0,09 & 0,73 & 0,02 & 1,57 & 2,19 \\
\hline Exxon & $9 / 2008$ & 0,12 & 0,86 & 0,05 & & 0,05 & 9,42 & 2,01 \\
\hline & $*$ & 0,08 & 0,87 & 0,04 & $-0,09$ & 0,05 & 10,63 & 1,65 \\
\hline Walmart & $5 / 2005$ & 0,20 & 1,10 & $-0,08$ & & 0,02 & 1,58 & 1,32 \\
\hline & $*$ & 0,27 & 1,08 & $-0,05$ & 0,38 & 0,02 & 0,98 & 1,85 \\
\hline Walmart & $9 / 2008$ & 0,12 & 0,83 & 0,04 & & 0,04 & 6,23 & 0,87 \\
\hline & $*$ & 0,53 & 1,03 & $-0,07$ & 0,87 & 0,03 & 4,86 & 1,79 \\
\hline Pfizer & $5 / 2005$ & 0,22 & 0,82 & 0,17 & & 0,04 & 1,91 & 0,33 \\
\hline & $*$ & 0,80 & 0,90 & 0,07 & 0,87 & 0,02 & 1,11 & 2,03 \\
\hline Pfizer & $9 / 2008$ & 0,20 & 0,85 & 0,06 & & 0,05 & 8,07 & 1,40 \\
\hline & $*$ & 0,26 & 0,95 & 0,00 & 0,49 & 0,04 & 3,87 & 1,79 \\
\hline J\&J & $5 / 2005$ & 0,29 & 0,91 & 0,06 & & 0,01 & 1,89 & 1,79 \\
\hline & $*$ & 0,28 & 0,91 & 0,05 & 0,13 & 0,01 & 1,67 & 1,88 \\
\hline J\&J & $9 / 2008$ & 0,00 & 0,88 & 0,00 & & 0,02 & 5,58 & 1,90 \\
\hline & $*$ & 0,04 & 0,89 & $-0,01$ & $-0,10$ & 0,02 & 6,87 & 1,27 \\
\hline HP & $5 / 2005$ & 0,18 & 0,88 & 0,22 & & 0,05 & 3,46 & 0,42 \\
\hline & $*$ & 0,72 & 1,02 & 0,09 & 0,83 & 0,03 & 2,18 & 2,09 \\
\hline HP & $9 / 2008$ & 0,39 & 0,97 & $-0,12$ & & 0,06 & 24,29 & 0,59 \\
\hline & $*$ & 0,69 & 1,00 & $-0,14$ & 0,71 & 0,04 & 9,50 & 1,46 \\
\hline Apple & $5 / 2005$ & 0,65 & 1,60 & $-0,69$ & & 0,06 & 2,92 & 0,88 \\
\hline & $*$ & 0,75 & 1,44 & 0,55 & 0,20 & 0,04 & 3,60 & 1,89 \\
\hline Apple & $9 / 2008$ & 0,79 & 1,34 & $-0,33$ & & 0,06 & 23,29 & 1,74 \\
\hline & $*$ & 0,78 & 1,32 & $-0,32$ & 0,09 & 0,07 & 19,65 & 1,75 \\
\hline Wells Fargo & $5 / 2005$ & 0,04 & 1,04 & $-0,02$ & & 0,01 & 1,28 & 1,12 \\
\hline & $*$ & 0,24 & 1,02 & 0,00 & 0,48 & 0,01 & 1,03 & 1,97 \\
\hline Wells Fargo & $9 / 2008$ & 0,22 & 0,93 & 0,15 & & 0,10 & 28,21 & 1,43 \\
\hline & $*$ & 0,28 & 0,94 & 0,14 & 0,29 & 0,10 & 20,26 & 1,79 \\
\hline Google & $5 / 2005$ & 0,35 & 1,59 & $-0,30$ & & 0,05 & 6,17 & 0,85 \\
\hline & $*$ & 0,47 & 151,62 & 0,13 & 1,00 & 0,03 & 3,17 & 2,16 \\
\hline & & & & & & & & \\
\hline & & $*$ & & &
\end{tabular}




\begin{tabular}{|l|l|r|r|r|r|r|r|r|}
\hline Company & Period & R2 & \multicolumn{1}{|c|}{$\boldsymbol{\eta}$} & \multicolumn{1}{c|}{ P } & $\boldsymbol{\varphi}$ & SEE & EER\% & DW \\
\hline Google & $9 / 2008$ & 0,24 & 1,00 & $-0,07$ & & 0,05 & 2,29 & 0,93 \\
\hline & $*$ & 0,41 & 0,90 & $-0,01$ & 0,64 & 0,04 & 5,87 & 2,17 \\
\hline Coca-Cola & $5 / 2005$ & 0,08 & 1,09 & $-0,03$ & & 0,01 & 6,47 & 0,60 \\
\hline & $*$ & 0,63 & 1,06 & 0,00 & 0,56 & 0,01 & 2,97 & 2,35 \\
\hline Coca-Cola & $9 / 2008$ & 0,53 & 1,12 & $-0,09$ & & 0,03 & 7,54 & 0,92 \\
\hline & $*$ & 0,79 & 0,89 & 0,02 & 0,92 & 0,02 & 3,76 & 2,01 \\
\hline IBM & $5 / 2005$ & 0,59 & 1,23 & $-0,36$ & & 0,03 & 6,39 & 0,60 \\
\hline & $*$ & 0,78 & 1,04 & $-0,17$ & 0,85 & 0,02 & 2,10 & 1,78 \\
\hline IBM & $9 / 2008$ & 0,00 & 0,91 & 0,00 & & 0,02 & 19,28 & 1,22 \\
\hline & $*$ & 0,13 & 0,90 & 0,01 & 0,31 & 0,03 & 13,96 & 1,94 \\
\hline
\end{tabular}

3.4.1 The First Tier of this part of testing covered on the daily basis one month time period in May 2005. Here the basic model's (Mode A) Coefficient of Determination $\mathrm{R}^{2}$ ranged from $3.4 \%$ (Exxon) to $65.1 \%$ (Apple) with the sample average 26.0\%. The EER forecast error factor reached $3.6 \%$ and the D-W statistics averaged 0.85 . The extended model (Mode B) shows the average $R^{2}$ value $55 \%$ within the range $80 \%$ (Pfizer) and $4.5 \%$ (Johnson \& Johnson). The EER and D-W indicators averaged $2.0 \%$ and 2.02 respectively. The increase of $\mathrm{R}^{2}$ in the Mode $B$ can be attributed to the effect of the complementary variable which together with a marginal increase of the expected serial dependence effect represented by the coefficient $\eta$ is also causing a decline in the short-term forecast indicator EER whilst the VIX Index sensitivity coefficient $\rho$ remained basically unchanged. This situation is also in line with the increase of the D-W statistic expressing a fall in the residuals' autocorrelation.

3.4.2 For the Second Tier testing the month of September 2008. the coefficient $\mathrm{R}^{2}$ shows for the Mode $A$ the average value $26.0 \%$ in the range $78.7 \%$ (Apple) and $1.0 \%$ (IBM) with the EER indicator and the D-W statistic revealing $13.4 \%$ and 1.3 values respectively. The Mode B indicates the $\mathrm{R}^{2}$ average value $40.0 \%$ in the range from $2.0 \%$ (Hewlett Packard) to $80.0 \%$ (Pfizer). The D-W statistic showed the average value 1.76. The forecast error EER factor indicated the average value 9.9\%. (For summary of average results refer to Tab. 9).

Results clearly again indicate a significant role of the complementary variable represented by the coefficient $\phi$ enhancing the model's general relationship in the form of a larger $\mathrm{R}^{2}$. This influence also supports a rise 
in the EER short-term forecast accuracy indicator and a fall of the D-W statistic.

A substantial decline of the expected serial dependence coefficient $\eta$. the volatility coefficient $\rho$ and the variable $\phi$. when both periods tested are compared, can be for both model's modes attributed to the stock market collapse in September 2008 associated with a decline of both market indices applied. This indicates a drop in accuracy of the expected volatility estimates as well as an impact of discontinuity concerning the serial dependence of securities' returns.

Tab. 9: Performance of securities' returns/VIX Index Summary of average results May 2005 \& Sept 2008

\begin{tabular}{|c|c|c|c|c|r|r|c|}
\hline \multicolumn{1}{|c|}{ Period } & $\mathbf{R}^{\mathbf{2}}$ & $\boldsymbol{\eta}$ & $\boldsymbol{\rho}$ & $\boldsymbol{\varphi}$ & \multicolumn{1}{|c|}{ EER } & \multicolumn{1}{c|}{ D-W } & \multicolumn{1}{c|}{ SEE } \\
\hline 5/2005 Mode A & 0.26 & 1.13 & 0.16 & - & 3.59 & 0.85 & 0.03 \\
\hline 5/2005 Mode B & 0.55 & 1.57 & 0.12 & 0.56 & 2.40 & 2.20 & 0.02 \\
\hline 9/2008 Mode A & 0.26 & 0.97 & 0.09 & - & 13.42 & 1.30 & 0.05 \\
\hline 9/2008 Mode B & 0.40 & 0.97 & 0.08 & 0.45 & 9.92 & 1.76 & 0.05 \\
\hline
\end{tabular}

\begin{tabular}{|l|l|l|}
\hline $\mathrm{R}^{2}$ ranges & Mode A 5/2005 & $3 \%-65 \%$ \\
\cline { 2 - 3 } & Mode A 5/2005 & $3 \%-80 \%$ \\
\cline { 2 - 3 } & Mode A $9 / 2008$ & $1 \%-79 \%$ \\
\hline & Mode A 9/2008 & $4 \%-79 \%$ \\
\hline
\end{tabular}

\section{Summary}

The model generated a substantial spread of results mainly explainable by the fundamental factors. However, generally it has shown a viability of the basic relationship consistent with its assumptions and a spectrum of quoted concepts and ideas related to various sources.

The general comparison of both models provides for a quantifiable assessment of the two causal elements of the process of generating the returns' expectations, i.e. the volatility as well as the serial dependence concerning the price returns' performance.

Again, considering the latter, it is possible to observe a substantial impact of the complementary variable $\phi$ on the overall significance of the general model's relationship thus offering a more comprehensive 
basis for prediction purposes. This is revealed by the difference in the coefficient $R^{2}$ indicating the serial effect of the past return's performance.

As a matter of fundamental underlying factor, what appears to make important difference between the model both versions' performance in the First Tier (2005) and the Second Tier (2008) is a shock pertinent to the market collapse in September 2008. This caused a situation of the "volatile volatility", seemingly complemented by a discontinuity "crack" of the serial dependence of security returns, leading to a fall in estimates' accuracy and therefore disjointed investors' decision-making; since . . ." you cannot predict anything with precision.

Forecasting volatility is like forecasting the weather. You can measure the intensity and path of a hurricane, and you can calculate the odds of its landing, but you cannot predict with confidence exactly it will land and how much damage it will do" (Mandelbrot and Hudson, 2006, p. 249).

\section{Conclusion}

"The Random Walk Hypothesis and its close relative the Efficient Market Hypothesis, have become icons of modern financial economics that continue to fire the imagination of academics and investment professionals alike" (Lo and MacKinlay. 1988. p. 6).

It is possible to say, that only few ideas in the area of Modern Finance have caused more controversy or held more profound implications than the theory of "efficient market" for risky securities and the corresponding models based on this concept. In an idealized world of "frictionless" markets and "costless" trading, the prices following the "random walk" are supposed to always fully reflect all available information and no extraordinary investment returns can be obtained.

However, in a perfectly "efficient" market investors would obtain in equilibrium only the risk-free return when due to the increasing proliferation of information and therefore a higher degree of predictability of serially dependent past returns any "excess" above the risk-free rate benchmark would be gradually arbitraged away by the risk-taking investors. Therefore, the market "efficiency" dynamics with the eventually identical investment horizons and equalized information costbearing and not bearing investors would have to finally cease.

Consequently, although the market efficiency framework represents one of the major revolutions in the investment management, it has become 
highly controversial all the way through, and particularly in the recent times critically disputed as being an oversimplified, unique as well as generally unrealistic concept. It is perhaps possible to say. that the doctrine of "market efficiency", in a dicey relation to the assumed "random walk" process is a mere illusion, no matter how much intuitively appealing, but still kicked around in the absence of any new, comprehensive approach to the reality concerning the capital markets' performance.

Since the onset of development of the Efficient Market Hypothesis, numerous attempts have been launched to capture the gist of the "real" capital market performance. The idea of price returns' distribution normality under conditions of uncertainty underlying the typical models such as the CAPM, Black \& Scholes, SIM, MIM, etc., have been gradually overcome and substituted by a more realistic view of the capital markets' contemporary behaviour.

Deterministic order of the pricing model frameworks under certainty, in which the future event is uniquely established by the past in the classical Newtonian sense, is certainly not universal and therefore there is a need to also understand situation of uncertainty and the state of a disorder. Chaos, the apparent randomness, as an expression of instability contrasting with regularity, is as such found everywhere in the nature and it is a part of our own environment as well as the human culture.

Therefore, the fundamental idea is that no matter how complex the systems may be they rely upon an underlying order. Very simple or small events can generate through such dependence on initial conditions a very complex behaviour of subsequent events in spite the inherent dynamic instability exhibiting itself for example in a lack of predictability.

The revolutionary ideas of Lo and MacKinlay, LeRoy (1973), E. Lucas (1978), as well as others and particularly of Mandelbrot and Hudson have set a new path along which the new, progressive research goes, being reinforced by the markets' turbulent behaviour observed in the recent years. Mandelbrot for example stated that the dimensions of an object are relative to the view of an observer and may be thoroughly fractional.

$\mathrm{He}$ argued that the proportion of information "error" of noise-containing time periods to the error-free periods was constant.

It follows, that an object whose irregularity is constant over different scales as a fractal phenomenon, can be infinitely extended whilst embracing a bound space. 
The information noise factors are therefore inevitable and must be considered in the modeling frameworks where discontinuous and generally unexpected sudden changes of the market prices can occur, whilst also a temporary duration of an "uneventful" price development takes place. Such performance patterns are of course inconsistent with any assumption of normally distributed events built into the "classical" models relied on the EMH.

The fractal performance of the market environment will have. on the one hand, always remained to some extend unpredictable in terms of its volatility, but on the other hand. it could be certainly approximated and possibly modeled for example in line with the Mandelbrot's analytical concept, underlying the two fundamental factors in forming the market price distribution in reflection of investors' decision-making.

Broadly speaking, such a model should in one way harness the "bearish" fear of loss confining an investor's decision to a reliance on the past performance, i.e. the serial dependence on the market "memory", whereas it also need to describe the "bullish" adventure trying to envisage the future market volatility, in order to possibly earn an extraordinary gain.

Therefore, the concept of "deterministic chaos" which combines in an integral way a causal approach respecting the immutable past and the stochastic probability view tapping the expected volatility fluctuations, can be used to derive a general framework of the workable model of asset pricing.

Consequently, a possible generation of new models should rather not dwell on for example the notion how the tested lack of serial dependence of price returns allegedly constituting a "proof" of the random walk process is providing for assessment of the market's efficiency profile. but instead to perhaps examine for example a correlation how fast the market prices react on certain blocks of new information.

Last but not least, as a matter of the more generalized approach. perhaps the Adaptive Market Hypothesis concept should be considered too "prices reflect as much information as dictated by the combination of environmental conditions and the number and nature of distinct groups of market participants each behaving in a common manner; a key insight of the AMH - taken directly from evolutionary biology - is that convergence to equilibrium is neither guaranteed nor likely to occur at any point in time. The notion that evolving system must march inexorably towards some ideal stationary state is plain wrong". (A.W. Lo, 2005, p.20). 
Kuklik, R. G. - Vacek, V.: Volatility Asset Pricing Model as an Alternative Approach?

On the basis of these generally outlined ideas, with the critical approach to the EMH and the RWM, supported by various arguments, the model VAPM was developed and applied using components of expected volatility and serial dependence to test its relationship with the market index S\&P500 as well as selected security returns.

Results, including the circumstances of the market implosion in 2008, show the more or less complemented influence in the form of interplay of these two enmeshed factors basically generating the capital market's dynamics. The tests covering various time periods, in spite of certain wider, but broadly explainable result data spread, generally confirmed the model's framework viability and its application potential envisaged in terms of the short term prediction routine, thus perhaps opening an avenue for a further analysis concerning its use and therefore possibly making a small contribution to the effort of moving research in the area of asset pricing models a step further.

\section{References}

[1] Cohen, K. J. - Poque, J. A. (1967): An Empirical Evaluation of Alternative Portfolio-Selection Models. Journal of Business, 1967, vol. 40, no. 2, pp. 166-193.

[2] Dodd, P. (1980): Merger Proposals. Management Discretion and Shareholders Wealth. Journal of Financial Economics. 1980, vol. 8, no. 2, pp. 105-137.

[3] Elton, E. - Gruber, M. (1981): Modern Portfolio Theory and Investment Analysis. Hoboken. Wiley. 1981.

[4] LeRoy, S. F. (1973): Risk Aversion and the Martingale Property of Stock Prices. International Economic Review. 1973. vol. 14, no. 2. pp. 436-446.

[5] Lo, A. W. (2005): Reconciling Efficient Markets with Behavioral Finances: The Adaptive Markets Hypothesis, Journal of Investment Consulting, 2005, vol. 7, no. 2, pp. 21-44.

[6] Lo, A. W. - MacKinlay A. C. (1988): Stock Prices do not follow Random Walk. Review of Financial Studies. 1988, vol. 1, no. 1, pp. 41-66.

[7] Lucas, R. E. (1978): Asset Prices in Exchange Economy. Econometrica. 1978. vol. 46, no. 6, pp. 1429-1445.

[8] Mandelbrot, B. - Hudson, R. (1997): Fractals and Scaling in Finance: Discontinuity. Concentration. Risk. Heidelberg, Springer Verlag, 1997. 
[9] Musílek, P. (2006): Trhy cenných papírů. Praha, Ekopress, 2006.

[10] Roll, R. (1977): A Critique of the Asset Pricing Theory's Tests. Part I: On Past and Potential Testability of the Theory. Journal of Financial Economics. 1977, vol. 4, no. 2, pp. 129-176.

[11] Sharpe, W. F. (1964): Capital Asset Prices: A Theory of Market Equilibrium under Conditions of Risk. Journal of Finance. 1964, vol. 19, no. 3, pp. 425-442. 
Kuklik, R. G. - Vacek, V.: Volatility Asset Pricing Model as an Alternative Approach.

\title{
Volatility Asset Pricing Model as an Alternative Approach?
}

Robert G. KUKLIK - Vladislav VACEK

\begin{abstract}
The reality of contemporary developments in the capital markets indicates that they do not lend themselves to the deductive theory based on simplified rationality of the physical world. The behaviour of the markets cannot be derived from rather bare postulates of the so called "random walk" process and the "normal distribution" of investments" returns. It in fact relates to a variety of different. even behavioural factors. The riskreturn relationship is not therefore stable over time and investors cannot rely on the comforting message that all you need to do in order to obtain an expected return is only to decide the appropriate level of risk. There are therefore serious doubts about the Efficient Market Hypothesis with e.g. the CAPM. SIM and MIM frameworks. The multifractal view of e.g. Mandelbrot concerning the market behaviour. has inspired the outline of the Volatility Asset Pricing Model (VAPM) based on the market's expected volatility and the serial dependence on the past return's performance. both reflecting the total market risk of an investment. In view of a further research this model has been so far successfully tested as well as presented.
\end{abstract}

Key words: Efficient Market Hypothesis; Random walk; Markowitz' mean-variance maxim; Multifractal view; CAPM; SIM; MIM; Total risk; Volatility; Serial dependence; VIX index; VAPM.

JEL classification: G12. 